\title{
ENROLADOS NA SACOLA PLÁSTICA ${ }^{1}$
}

\author{
Antonio Carlos Rodrigues - tonimacr@ gmail.com \\ Universidade Federal de Minas Gerais, Belo Horizonte - MG, Brasil
}

KELLY DE MORAIS - kellyadm2@ gmail.com

Universidade Federal de Minas Gerais, Belo Horizonte - MG, Brasil

Era início de mais um dia nublado na capital mineira. Alfredo fechou o jornal e, durante alguns minutos, ficou parado no meio da sala, refletindo sobre o que acabara de ler. Já havia lidado com questões legais antes, mas agora, diante dessa nova situação, não sabia bem por onde começar. A capa do jornal apresentava a seguinte manchete: "Lei que proíbe uso de sacolas plásticas em Belo Horizonte entra em vigor a partir do mês de abril".

- É... Mais uma imposição da Prefeitura que teremos que cumprir. Preciso falar com Márcio - disse Alfredo.

Assim, pegou a chave do carro e seguiu ao encontro de seu sócio.

\section{Como tudo começou}

A padaria Pão Delícia teve seu início em maio de 1982, quando o Sr. Rafael e sua esposa, Dona Paula, decidiram abrir uma padaria no bairro onde moravam. O casal acreditava que, naquela região, não havia nenhuma panificadora que oferecesse produtos de qualidade, motivo pelo qual perceberam, naquele negócio, uma oportunidade de melhorar as condições de vida da família.

O ano de 1979 havia sido muito difícil para eles. Dona Paula havia perdido o emprego de confeiteira em uma padaria de médio porte na cidade. O Sr. Rafael, por sua vez, sofrera um acidente no torno mecânico da empresa onde trabalhava, o que resultou na amputação de três de seus dedos da mão direita.

Ao fim do processo que correu na Justiça por três anos, o Sr. Rafael recebeu os devidos valores trabalhistas e a indenização por acidente de trabalho, o que lhe rendeu dinheiro suficiente para a abertura do novo negócio. Com essa quantia, a experiência de Dona Paula e a ajuda dos filhos - Alfredo e Márcio - parecia fácil tocar o novo empreendimento.

Após localizarem o ponto comercial para a padaria, numa rua movimentada de um bairro de classe média, e se instalarem lá, o maquinário básico foi adquirido de outro estabelecimento. As primeiras fornadas de pães foram produzidas com as receitas e as mãos de Dona Paula, que dedicava a maior parte de seu dia às atividades da padaria. O Sr. Rafael ocupava-se com os fornecedores, os

\footnotetext{
${ }^{1}$ Os nomes da empresa e dos personagens são fictícios para preservar as fontes do caso real.
} 
empregados e as finanças. Assim, durante os quatro primeiros anos, a empresa funcionou na informalidade.

Com o crescimento de vendas observado a partir dos primeiros meses de 1983, a padaria já vendia cerca de 1.000 pães por dia. Os produtos oferecidos eram básicos (pães de sal, pães doces, bolos e biscoitos), entretanto, houve um aumento na qualidade desses produtos, devido à aquisição de novas máquinas e à contratação de novos profissionais. A principal dificuldade enfrentada pelo casal, todavia, era a falta de capital de giro para a aquisição da matéria-prima.

Como operavam na informalidade, só conseguiam comprar farinha de trigo e outros ingredientes em revendedores locais, que cobravam mais caro e ofereciam prazos menores, quando ofereciam. Por essa razão, o casal decidiu regularizar o empreendimento, constituindo formalmente a empresa.

Com a formatura de Alfredo no curso de Administração, em dezembro de 1986, o Sr. Rafael e a Dona Paula transferiram o controle da padaria para os filhos, que passaram a administrar o negócio em sociedade. Enquanto Márcio ocupava-se com o dia a dia da padaria, Alfredo se responsabilizava por questões financeiras e legais, tais como impostos e normas sanitárias.

A formalização da padaria Pão Delícia permitiu maior volume de compras, o que acarretou na redução de preços de alguns produtos. Apesar das implicações dessa decisão em relação ao pagamento de impostos e de encargos, ela também possibilitou aumentar a gama de fornecedores e de produtos comercializados. A partir daí, a padaria passou a oferecer a seus clientes não somente produtos de fabricação própria mas também itens industrializados, como produtos componentes da cesta básica, bebidas e produtos de higiene pessoal.

Na década de 1990, o negócio continuou prosperando e, atualmente, a padaria Pão Delícia constitui-se como uma microempresa. Houve crescimento no número de clientes, motivado pela expansão imobiliária verificada no bairro naquela época e ainda em vigor nos dias atuais.

Os irmãos acreditam que o sucesso da padaria Pão Delícia justifica-se por seus produtos de qualidade e também pela proximidade que, orgulhosamente, Márcio mantém com seus clientes, conhecendo-os pelos nomes.

Até o ano de 2011, Alfredo e Márcio haviam lidado bem com as questões legais relativas às atividades da padaria. A partir desse ano, entretanto, depararam-se com a nova lei referente ao uso das sacolas plásticas.

\section{A lei das sacolas plásticas}

A Lei Municipal n. 9.529/2008, regulamentada pelo Decreto n. 14.367, de 12 de abril de 2011, dispõe sobre a substituição do uso de sacolas plásticas feitas de derivados do petróleo. A proibição de sacos feitos de polietileno ${ }^{2}$ incide sobre qualquer tipo de estabelecimento comercial, como supermercados, padarias, lojas, drogarias e outros. A regra vale para estabelecimentos privados, entidades e órgãos públicos da capital.

Apesar de a lei ter entrado em vigor há três anos, até fevereiro de 2011 a utilização das tradicionais sacolas plásticas era facultativa. A solução, apresentada pela própria legislação, é sua substituição por sacolas ou sacos de lixos ecológicos.

\footnotetext{
${ }^{2}$ Composto químico resultante de reações químicas de polimerização.
} 
De acordo com a lei, há duas opções de sacolas ecológicas que poderão ser utilizadas em substituição às tradicionais. São elas:

- Sacolas biodegradáveis compostáveis: produzidas com matéria orgânica, geralmente feita de amidos (milho, mandioca ou batata) ou do bagaço de cana-de-açúcar. Apresentam fácil decomposição, degradando-se em até 180 dias, além de não poluir nem deixar resquícios de toxidade. O produto, porém, deve apresentar um selo informando que atende as normas da Associação Brasileira de Normas Técnicas (ABNT).

- Sacolas retornáveis: feitas com materiais variados, como $\mathrm{TNT}^{3}$, tecido, palha, ráfia, material reciclável, entre outros, que permitem um longo período de utilização.

A Prefeitura de Belo Horizonte concedeu, até 16 de agosto de 2011, a permissão do uso das sacolas biodegradáveis compostáveis sem selo da ABNT e das sacolas recicladas (feitas com plástico reciclável e sobras de produção), sendo permanentemente proibida a circulação das sacolas de plástico convencionais (produzidas à base de petróleo, descartáveis e com tempo de decomposição de até 400 anos) e das sacolas oxi-biodegradáveis (compostas de polímero de petróleo com o aditivo $\mathrm{D} 2 \mathrm{~W}^{4}$ ).

O estabelecimento que descumprir a lei está sujeito desde a uma simples notificação, passando por multas de $\mathrm{R} \$ 1.000,00$ ou $\mathrm{R} \$ 2.000,00$, interdição do estabelecimento e até mesmo cassação do alvará de localização e de funcionamento de suas atividades.

A Associação Mineira de Supermercados (AMIS), o Sindicato e Associação Mineira da Indústria de Panificação (Amipão), a Associação Comercial de Minas (ACMinas), a Câmara de Dirigentes Lojistas de BH (CDL-BH), a Federação do Comércio de Bens, Serviços e Turismo do Estado de Minas Gerais (Fecomércio-MG), o Movimento das Donas de Casa e Consumidores de Minas Gerais (MDC-MG), a Prefeitura Municipal de Belo Horizonte e a Procuradoria de Proteção e Defesa do Consumidor (PROCON) Municipal assinaram um protocolo de intenções que firma o compromisso das instituições em colaborar para o sucesso da lei.

Para isso, as entidades lançaram a campanha educativa Sacola Plástica Nunca Mais (ver figura no Anexo 1), que busca conscientizar a população e os comerciantes da importância de seguir a lei. Instituiu-se a venda de sacola retornável compostável no comércio varejista ao valor fixo de $\mathrm{R} \$ 0,19$ a unidade. A cobrança pelo produto ocorre para estimular a utilização da sacola retornável, vendida por $\mathrm{R} \$ 1,98$ a unidade nos pontos de varejo participantes da campanha.

\section{O que é feito lá fora?}

Alguns países adotaram leis rígidas contra o consumo de sacolas plásticas. A China, por exemplo, proíbe a distribuição gratuita e a produção de sacolas plásticas com espessura inferior a 0,025 milímetros, com o intuito de que a população use bolsas de tela e cestas para fazer as compras. Os comerciantes que infringirem a lei estão sujeitos a multa estipulada pelo governo.

A Irlanda instituiu a cobrança de pesados impostos revertidos em projetos ambientais. A medida adotada pelo governo irlandês modificou o hábito dos consumidores e diminuiu o uso do produto.

\footnotetext{
${ }^{3}$ Sigla para Tecido Não Tecido, produzido a partir de fibras desorientadas aglomeradas e fixadas, não passando pelos processos têxteis mais comuns, que são fiação e tecelagem (ou malharia).

${ }^{4}$ Aditivo granulado que, ao ser introduzido no processo de fabricação de um produto plástico, torna esse produto degradável em um tempo significativamente menor, quando comparado ao plástico convencional.
} 
Algumas cidades americanas utilizam normas de proibição de sacolas plásticas. São Francisco foi a primeira metrópole a proibir o uso de sacolas plásticas em grandes supermercados e farmácias. Apenas sacolas compostas por derivados de milho ou de papel reciclado podem ser utilizadas. A coleta de lixo é feita em coletores seletivos especiais, que não aceitam o depósito de sacolas plásticas. Nesse caso, os resíduos orgânicos devem ser embalados em papel, jornal ou sacos feitos de matéria-prima orgânica renovável. Na Califórnia, existe um programa de reciclagem de sacolas plásticas, que obriga o comerciante a ter recipiente de coleta apropriado "em lugar proeminente e visível" para recolher sacolas que seriam recicladas. Em Nova Iorque, o prefeito da cidade sancionou uma lei que exige que grandes lojas tenham programas de reciclagem e disponibilizem sacolas recicláveis.

Alemanha, Austrália, Bangladesh, Bélgica, Dinamarca, França, Noruega, Inglaterra e Japão são exemplos de países que também adotaram medidas para redução do uso das sacolas plásticas tradicionais.

\section{Lidando com a nova lei}

Apesar de a nova lei ter entrado em vigor há três anos, até o mês de fevereiro de 2011 nenhum dos sócios da padaria havia tomado conhecimento de seu conteúdo nem das implicações que seu cumprimento traria para o cotidiano da empresa. Alfredo foi o primeiro a se inteirar do assunto, ao ler a reportagem de um jornal local.

Em fevereiro, os estoques de sacolas convencionais da panificadora ainda estavam cheios. Um novo pedido de 40 fardos (1.000 unidades cada), mínimo exigido pelo fornecedor, havia sido feito no fim de dezembro, quantidade suficiente para suprir as necessidades da empresa até o mês de junho. Como essas sacolas não poderiam mais ser distribuídas a partir de abril, entretanto, Alfredo já contabilizava os prejuízos.

O relacionamento de oito anos com o fornecedor de sacolas plásticas Plasticel não poderia ser preservado, uma vez que essa empresa não produzia as sacolas de acordo com as especificações requeridas. A descontinuidade dessa parceria causava preocupação aos sócios, os quais afirmavam que, se não fossem obrigados a seguir a lei, nunca optariam pela mudança de fornecedor nem pela mudança das sacolas. "Foram mudanças impostas pela legislação", diziam eles.

Alfredo e Márcio não acreditavam que essa nova lei pudesse de fato contribuir para a preservação do meio ambiente ou mesmo que ela fosse um passo adiante rumo a um consumo mais consciente de recursos. "Mudar o material de que é feito a sacola não vai mudar a consciência das pessoas", relatavam os sócios, que ainda afirmavam: "a lei não vai pegar".

A procura por um novo fornecedor começou no início de março, após os sócios se inteirarem das especificidades da nova lei. Com grande dificuldade, após alguns dias e várias ligações, eles conseguiram contatar a Uniplast, única fornecedora de sacolas biodegradáveis do Estado. O preço, no entanto, assustou Alfredo: enquanto as sacolas tradicionais custavam $\mathrm{R} \$ 0,02$, a nova alternativa custaria R \$ 0,19. "Repassaremos para nossos clientes o valor da sacola biodegradável? Essa nova despesa trará grandes impactos à nossa planilha de custos. O que você acha?”, questionava Alfredo. 


\section{O que fizeram as outras padarias?}

Assim como a padaria Pão Delícia, os demais estabelecimentos de belo-horizontinos foram obrigados a se enquadrar nas regulamentações da Lei Municipal n. 9.529/2008.

Alfredo foi visitar algumas panificadoras para verificar o que elas haviam feito. Das três padarias visitadas, todas já ofereciam a sacola biodegradável e haviam repassado para o cliente o seu preço de custo. Alfredo imediatamente se perguntou como esses clientes haviam recebido a notícia de que deveriam arcar com mais um custo ao realizar as compras. Não se sentiu à vontade, no entanto, para fazer questionamentos a ninguém, e constatou que as três padarias haviam também adotado a venda não somente das sacolas biodegradáveis, mas de bolsas retornáveis confeccionadas com pano ou com materiais sintéticos.

\section{O impasse entre os sócios}

Alfredo e Márcio foram ao escritório da padaria e lá iniciaram uma discussão sobre as implicações do cumprimento da nova lei. Alfredo disse a Márcio que havia entrado em contato com um representante comercial da Uniplast e descoberto que o preço unitário da sacola biodegradável era muito superior ao pago pela sacola convencional.

Assim, existiam duas alternativas possíveis diante da imposição legal: ou repassariam esses custos para os clientes ou arcariam com eles. A média mensal de consumo de sacolas plásticas é de 6.500 unidades. As duas sacolas são repassadas a preço de custo. Os custos unitários das sacolas antigas e das novas são, respectivamente, $\mathrm{R} \$ 0,02$ e $\mathrm{R} \$ 0,19$. Apesar de Alfredo não ter analisado profundamente a questão financeira, já estava convicto de que a melhor opção, considerando apenas os custos unitários, seria repassar os custos das novas sacolas aos consumidores finais.

Alfredo disse ainda que, como em outros estabelecimentos, a padaria Pão Delícia poderia vender bolsas retornáveis ao valor unitário de $\mathrm{R} \$ 1,98$. Para ele, a economia gerada pela interrupção da compra de sacolas tradicionais e o repasse do custo das sacolas biodegradáveis aos clientes representaria uma despesa a menos com a qual se preocupar.

Assim, na opinião de Alfredo, a questão estaria decidida. Márcio, entretanto, não concordava com os argumentos do irmão. Alfredo lidava com as questões administrativas da empresa e, portanto, mantinha pouco contato com os consumidores. Márcio, por sua vez, orgulhava-se por manter um relacionamento próximo com os clientes, fato que representava um diferencial em comparação com outros estabelecimentos de grande porte. Assim, Márcio sabia que o repasse desse custo poderia impactar negativamente sobre as vendas da padaria.

Márcio, inclusive, já ouvira falar de um supermercado próximo à padaria no qual as vendas haviam diminuído em virtude da nova lei. Como não havia mais sacolas de distribuição gratuita, os clientes passaram a comprar menos porque não tinham como carregar muitos itens. Márcio acreditava que essa era uma resposta dos consumidores ao repasse do custo da sacola ecológica e que isso poderia ocorrer na padaria Pão Delícia.

Outras questões ainda atormentavam Márcio. Como sua relação com os clientes era muito próxima, ele sabia que não haveria como recusar uma sacola a um cliente que comprava em seu estabelecimento há mais de 15 anos, por exemplo. Ele sabia também que, se oferecesse a sacola gratuitamente para um cliente desse tipo, não haveria possibilidade de pedir aos demais que pagassem por ela. Márcio imaginou como se sentiria constrangido em pedir aos seus clientes que pagassem pelas sacolas, sobretudo aqueles mais antigos, para os quais qualquer custo adicional nas compras poderia não ser aceito de modo natural. 
"E se o cliente sair de casa sem intenção de fazer compras e só depois perceber que precisa de alguma coisa? Mesmo que ele já tenha comprado sacola retornável antes, provavelmente terá que comprar outra para levar os produtos para casa", dizia Márcio. "Além disso, grande parte das donas de casa usa as sacolinhas para embalar o lixo doméstico.” Assim, para ele, a nova lei representaria redução no número de clientes e no volume de vendas. Enquanto olhava para Alfredo, Márcio não parava de se perguntar:

- Como lidar com essa nova lei? Será que devemos repassar os custos? Será que o custo da nova sacolinha implicará a redução do número de clientes? Como eles receberão essa notícia? Como reverter essa situação? 


\section{Anexo 1}

Logomarca da campanha Sacola Plástica Nunca Mais

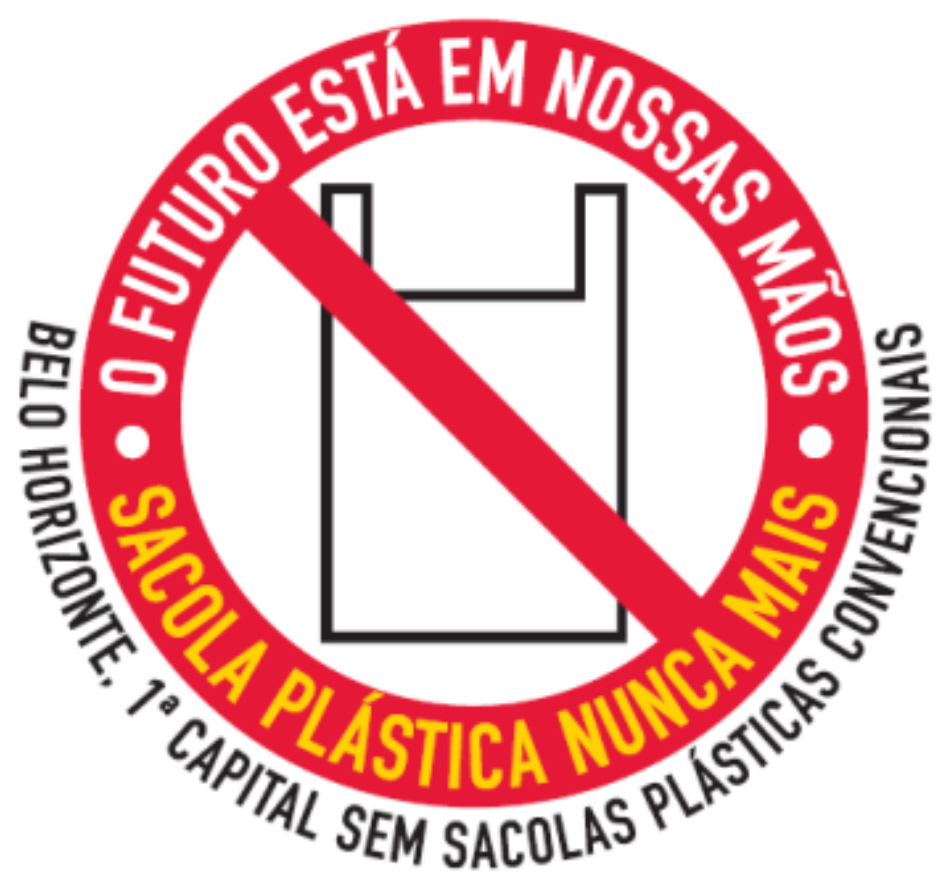

Fonte: Disponível em http://portalpbh.pbh.gov.br/pbh /. Acesso em 20.05.2011. 